Please do not remove this page

RMIT

UNIVERSITY

\title{
Thermal peformance of miniature loop heat pipe operating under different heating modes
}

Singh, Randeep; Akbarzadeh, Aliakbar; Mochizuki, Mastaka; Sajtoy, Yuji; Nguyen, Thang; Kiyooka, Fumitoshi; Wuttijumnong, Vijit

https://researchrepository.rmit.edu.au/esploro/outputs/9921862533301341/filesAndLinks?institution=61RMIT_INST\&index=null

Singh, R., Akbarzadeh, A., Mochizuki, M., Sajtoy, Y., Nguyen, T., Kiyooka, F., \& Wuttijumnong, V. (2006). Thermal peformance of miniature loop heat pipe operating under different heating modes. ITHERM '06, 557-562. https://doi.org/10.1109/ITHERM.2006.1645394

Published Version: https://doi.org/10.1109/ITHERM.2006.1645394

Repository homepage: https://researchrepository.rmit.edu.au

(c) 2006 IEEE. Personal use of this material is permitted. However, permission to reprint/republish this material for advertising or promotional purposes or for creating new collective works for resale or redistribution to servers or lists, or to reuse any copyrighted component of this work in other works must be obtained from the IEEE.

Downloaded On 2023/04/26 23:39:29 +1000 


\title{
THERMAL PERFORMANCE OF MINIATURE LOOP HEAT PIPE OPERATING UNDER DIFFERENT HEATING MODES
}

\author{
Randeep SINGH, Aliakbar AKBARZADEH \\ Energy CARE Group, RMIT University, \\ Bundoora East Campus, Bundoora 3083, Melbourne, Australia
}

\author{
Mastaka MOCHIZUKI*, Yuji SAITO, Thang NGUYEN, Fumitoshi KIYOOKA, Vijit WUTTIJUMNONG \\ Thermal Technology Division, R \& D Department, Fujikura Ltd., \\ 1-5-1, Kiba, Koto-Ku, Tokyo 135-8512, Japan, \\ Tel: +81 35606 1174, Fax: +81 35606 1514, Email:mmotizuk@fujikura.co.jp
}

\begin{abstract}
In the new generation microprocessors, it is observed that the power density over the active surface can vary from uniform to non uniform modes depending on the clock speed and the processing load on the chipset. The latter mode of operation can result in hot spots on the microprocessors that can result in the increase of the local temperature above the permissible limit and ultimately in the failure of the electronic device. In order to propose a solution for this problem a miniature Loop Heat Pipe (mLHP) with the flat disk shaped evaporator, $30 \mathrm{~mm}$ in diameter and $10 \mathrm{~mm}$ thick, was developed. The proposed mLHP was tested under uniformly as well as nonuniformly heating mode. In the uniform heating, the entire active area of the evaporator was heated while in the nonuniform mode only $14 \%$ of the evaporator active area was heated locally. The thermal performance of the mLHP under these heating modes was compared on the basis of the evaporator wall temperature and thermal resistance between different loop components. The results of the experiment help to classify mLHP as the viable thermal solution for the cooling of microprocessors with local hot spots and non-uniform heating patterns.
\end{abstract}

KEYWORDS: Miniature Loop Heat Pipe, mLHP, LHP, Thermal Control, local hot spots, non-uniform heating, Electronics Cooling, Flat Evaporator.

\section{NOMENCLATURE}

$\mathrm{R} \quad$ Thermal resistance, ${ }^{\circ} \mathrm{C} / \mathrm{W}$

$\mathrm{T} \quad$ Temperature, ${ }^{\circ} \mathrm{C}, \mathrm{K}$

$Q^{\bullet} \quad$ Applied heat load, W

$\begin{array}{ll}\text { Subscripts } \\ a & \text { ambient } \\ c c & \text { compensation chamber } \\ c & \text { condenser } \\ e & \text { evaporator } \\ h & \text { heater } \\ h p & \text { heat pipe }\end{array}$

0-7803-9524-7/06/\$20.00/@2006 IEEE

$\begin{array}{ll}i & \text { inlet } \\ o & \text { outlet } \\ t & \text { total } \\ w & \text { wall }\end{array}$

\section{INTRODUCTION}

With the advent of the high performance and compact microprocessors, the power dissipation tendency of the electronic devices is continually on the rise. The increase in the processing speed of the microprocessors with the growth of the integrated circuits on them and decrease in the heat dissipating area of the chip for space and weight conservation in the portable and handheld devices like laptops and palmtops have resulted in very high and concentrated heat fluxes. Depending upon the design constraints and thermal requirements, two phase cooling technology has emerged with different options that can be considered in the thermal management of these devices. Loop Heat Pipe (LHP) (Maydanik, 2004) is one of the outcomes of the two phase technology that has acquired global acceptance in the thermal control of the ground based as well as space based electronics.

LHPs are considered to be highly reliable heat transfer devices that work on the basis of the capillary pumping of the working fluid. These devices use latent heat of evaporation of the working fluid to transfer large heat loads from heat acquisition component (or evaporator) to heat rejection component (or condenser). LHP is an improvement over the conventional heat pipe in which the capillary structure is present locally inside the evaporator active zone and the liquid vapour phases are thermally and spatially separated from each other. Due to these unique design features, LHP are able to transfer large thermal loads up to distance of several meters at any orientation in the gravity field. At present, LHPs have been successful implemented as a thermal control technology for electronics in spacecrafts (Swanson, 2004) and satellites. Computer cooling is another field where the thermal potential of the LHPs is been explored recently. In this case, cooling devices are required to work favourably in the 
horizontal orientation (i.e. evaporator and condenser at the same level) but at the same time high and concentrated heat fluxes have to be handled along the torturous path due to space constraints. In LHPs, this is made possible by using wickless transport lines that can be easily bent and adapted to the available space. Another requirement to employ LHP for the cooling of the computer microprocessors especially for the portable computers is to evaluate their viability at the miniature scale. For this purpose, different variants of the miniature LHP (mLHP) have already been developed and successful tested.

Evaporator being the main component of the LHP needs special attention for its design. By now, evaporator with flat as well as cylindrical shapes has been developed. Nonetheless, it is justifiable that for cooling devices like laptops with limited thickness, flat evaporator geometry is the best option. Delil et al (2002) developed mini LHP with a flat disk shaped evaporator, $44 \mathrm{~mm}$ diameter and $22 \mathrm{~mm}$ thickness. The device was able to transfer $120 \mathrm{~W}$ maximum power and its thermal resistance lies in the range of 0.32 $1.62{ }^{\circ} \mathrm{C} / \mathrm{W}$. mLHP with flat rectangular shaped evaporator, $40 \mathrm{~mm}$ by $50 \mathrm{~mm}$ area and $30 \mathrm{~mm}$ thickness, was tested (Boo \& Chung, 2005) using $35 \mathrm{~mm}$ by $35 \mathrm{~mm}$ active heating zone with different working fluids. A prototype of ammonia mLHP was developed (Pastukhov et al, 2003) with flat rectangular evaporator $5.5 \mathrm{~mm}$ in thickness and heat transfer length of $75 \mathrm{~mm}$. Different variants of ammonia mLHPs with flat disk-shaped evaporators of stainless steel with an active zone diameter of $30 \mathrm{~mm}$ and thickness in the range from 10 to $13 \mathrm{~mm}$ were developed and successfully tested at the ITP (Institute of Thermal Physics), Russia (Chernysheva et al, 2002).

For most of these prototypes the potential of the mLHP was evaluated at the uniformly heating modes of the evaporator. In this mode the heating is done on the whole of the evaporator active zone i.e. the surface where capillary structure makes contact with the evaporator wall and there are vapour removal channels. In actual practice consequences can arise in which only part of the active zone may be heated due to local heating or hot spots on the heat source. For this purpose, the thermal characteristics of the LHP should be studied at non uniform heating mode in which only part of the active zone is heated. The second mode of heating is very important from the point of view of microprocessors that can involve local hot spots and irregular surface heating pattern depending upon the data processing load.

In light of the above discussion, the present study was conducted to test and compare the thermal performance of the mLHP under uniformly and non-uniformly heating mode. mLHP with flat disk shaped evaporator of $30 \mathrm{~mm}$ active zone diameter and total thickness of $10 \mathrm{~mm}$ was developed from copper. Heat load simulators of two different sizes were used to heat fully or part of the active zone of the mLHP evaporator. The results of experiment confirm the acceptable functioning of the mLHP for both uniform and non uniform heat supply.

\section{EXPERIMENTAL PROTOTYPE}

The schematics of the mLHP are as shown in Fig 1 and consist of capillary evaporator, fin-and-tube condenser, vapour and liquid transport lines and compensation chamber.

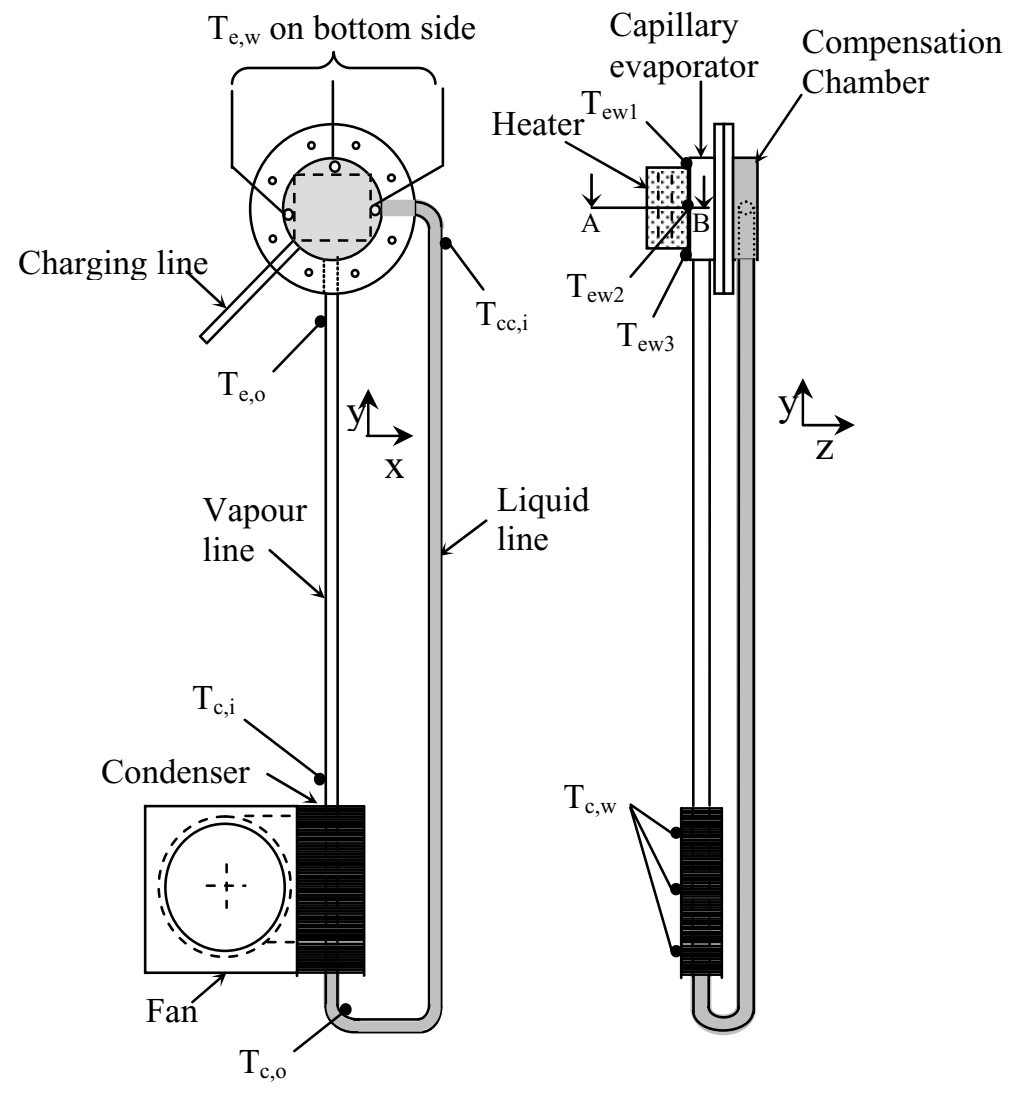

Fig 1. Schematics of mLHP showing different components and test set up

The capillary evaporator constitutes the ramified system of vapour removal channels and the wick structure. The thickness of the evaporator also includes the compensation chamber that stores the excess inventory of the working fluid and helps in the self priming of the capillary structure during startup and normal operation of the mLHP.

The condenser was made in the form of fin heat exchanger with the total length of $50 \mathrm{~mm}$. mLHP body and the transport lines were made of copper. Water which is fully compatible with copper material was used as the working fluid. The charging inventory of the working fluid was decided on the basis of the volume of the liquid line, compensation chamber and porous bulk of the capillary structure such that $50 \%$ of the compensation chamber is occupied with the working fluid in the cold state (i.e. when the mLHP is not operating). The dimensions for the main parameters of $\mathrm{mLHP}$ are listed in Table 1. 
Table 1. Main Design Parameters of the mLHP

\begin{tabular}{|l|l|}
\hline Parameter & Value \\
\hline Evaporator Shape & $\begin{array}{l}\text { Flat Disk } \\
\text { Shaped }\end{array}$ \\
\hline $\begin{array}{l}\text { Evaporator heating face } \\
\text { diameter, (OD/ID) cm }\end{array}$ & $30 / 28$ \\
\hline $\begin{array}{l}\text { Heat Load simulator area (heater } \\
\text { size), } \mathrm{cm}^{2}\end{array}$ & $6.25,1$ \\
\hline Body Material & Copper \\
\hline Wick Material & Nickel \\
\hline Wick Effective Pore radius, $\mu \mathrm{m}$ & $3-5$ \\
\hline Vapour Line Length, mm & 65 \\
\hline Liquid Line Length, mm & 200 \\
\hline $\begin{array}{l}\text { Vapour/Liquid Line Diameter } \\
\text { (Internal/External), mm }\end{array}$ & $2 / 3$ \\
\hline Condenser Type & External Fins \\
\hline Condenser Length, mm & 50 \\
\hline Working Fluid & Water \\
\hline
\end{tabular}

\section{TESTING METHOD}

mLHP was tested under condition of uniform heating using heater of $6.25 \mathrm{~cm}^{2}\left(25 \times 25 \mathrm{~mm}^{2}\right)$ area and non uniform heating using heater of $1 \mathrm{~cm}^{2}\left(10 \times 10 \mathrm{~mm}^{2}\right)$ area. For nonuniformly heating, only part of evaporator active zone is supplied with heat. Here, non uniform heating was done on approximately $14 \%$ of the evaporator active zone. Heat load simulators were in the form of copper block embedded with two cylindrical cartridge heaters as shown in Fig 2. During testing heat source was attached symmetrically to the center of the circular heat absorbing face.

The condenser cooling was provided by air cooling fan using ambient air with a temperature of $24 \pm 2^{\circ} \mathrm{C}$. Heat load input to the simulator source was measure and control using digital powermeter. The power input to the heat simulator was increase in step of $5 \mathrm{~W}$ during the test. In accordance with the thermal requirements of the microprocessors, the maximum input power was limited by the maximum permissible temperature of the heat source i.e. $100 \pm 5^{\circ} \mathrm{C} . \mathrm{K}$ Type thermocouples with maximum error of $\pm 0.1^{\circ} \mathrm{C}$ were used to measure and monitor temperature at different points on the mLHP. Fig 1 also shows the experimental set up for testing the mLHP along with the location of the thermocouples. The shaded portion in the figure shows the volume of the mLHP occupied by liquid while the non shaded portion depicts the volume occupied by the vapour phase. The thermal performance of the mLHP under different heating modes was compared on the basis of the evaporator surface temperature, evaporator thermal resistance, $\mathrm{mLHP} /$ heat pipe thermal resistance and total thermal resistance of the device. The following relations were used to calculate the thermal resistances.

Evaporator thermal resistance

$R_{e}=\left(\frac{\left(T_{e, w}-T_{e, o}\right)}{Q^{\bullet}}\right.$
Heat Pipe thermal resistance

$$
R_{h p}=\left(\frac{\left(T_{e, w}-T_{c, w}\right)}{Q^{\bullet}}\right.
$$

Total thermal resistance

$$
R_{t}=\frac{\left(T_{h}-T_{a}\right)}{Q^{\bullet}}
$$

For measuring the temperature of the heat source, thermocouple was fixed in the special groove machined in the center of the heater active surface as shown in Fig 3.

Temperature of the evaporator surface was calculated by averaging the temperatures of the three thermocouples fixed on the evaporator active zone. Depending on the applied heat load, the wall/surface temperature of the condenser was estimated either on the basis of the condenser outlet temperature or mean of the readings given by the thermocouples fixed along the length of the condenser.

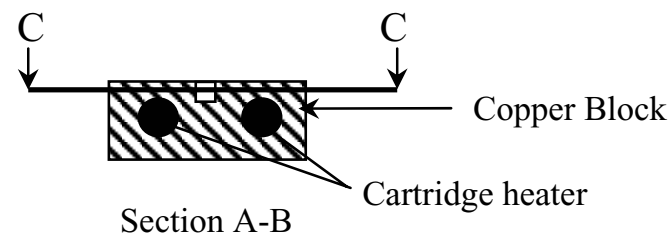

Fig 2. Cross sectional view of the heat load simulator

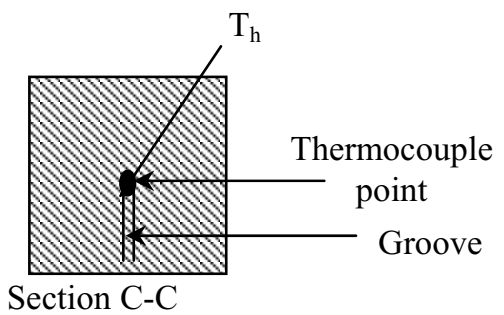

Fig 3. Sectional view of the active face of the heat load simulator showing thermocouple location

Testing of the mLHP prototype was done in the horizontal configuration with evaporator and condenser at the same level. Start up of mLHP was assumed to occur with the rise in temperature at evaporator outlet and all over the vapour line. For successful startup, the temperature at the evaporator outlet and the condenser inlet should be maintained within $\pm 1{ }^{\circ} \mathrm{C}$. For a given heat load, steady state was characterized by the constant evaporator temperature. 


\section{RESULT AND DISCUSSION}

Heat load applied to the active zone of the evaporator results in the formation of vapours inside the evaporator grooves. These vapours can form as a result of boiling, if the liquid is completely flooding the grooves or from the evaporation of liquid from the partial filled grooves and evaporating face of the wick. The startup phenomenon is mainly dictated by the pre startup liquid distribution inside the evaporator grooves and compensation chamber. As a result of the vapour formation inside the evaporation zone, the liquid is cleared from the grooves and vapour line. The displaced liquid is accommodated inside the compensation chamber and the stable evaporating meniscus is formed at the wall wick interface inside the evaporation zone.
Depending upon the applied heat load, such a liquid-vapour interface also exists inside the compensation chamber and the condenser. mLHP registered successful startup under different modes of heating. Fig 4 and 5 shows the startup characteristics of the mLHP for the uniform heating (using $25 \times 25 \mathrm{~cm}^{2}$ source) and partial or non-uniform heating (using 10x10 $\mathrm{cm}^{2}$ source) under $20 \mathrm{~W}$ input power respectively.

The startup process was very reliable in the range of applied power and the mLHP evaporator does not showed any indication of wick dry-outs like evaporator temperature overshot, back flow of the vapour to the compensation chamber etc.

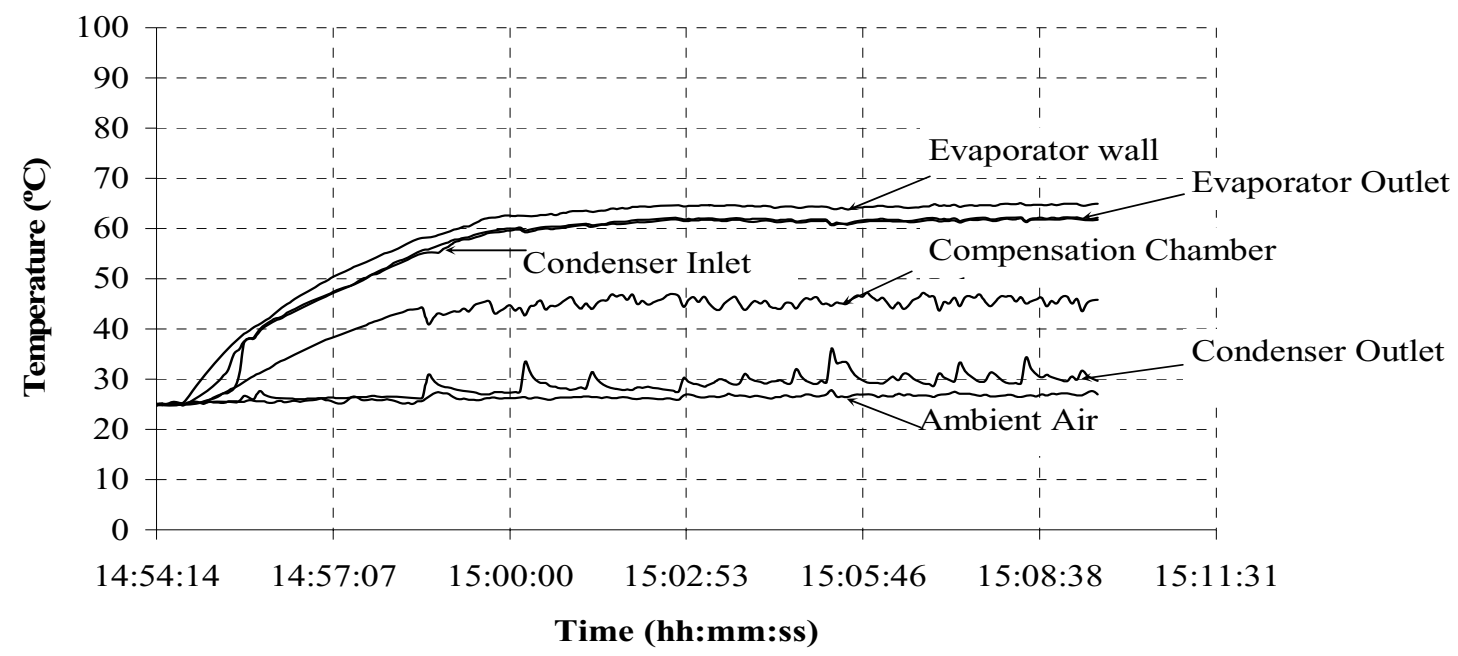

Fig 4. Start up of the mLHP under uniform heat load of $20 \mathrm{~W}$

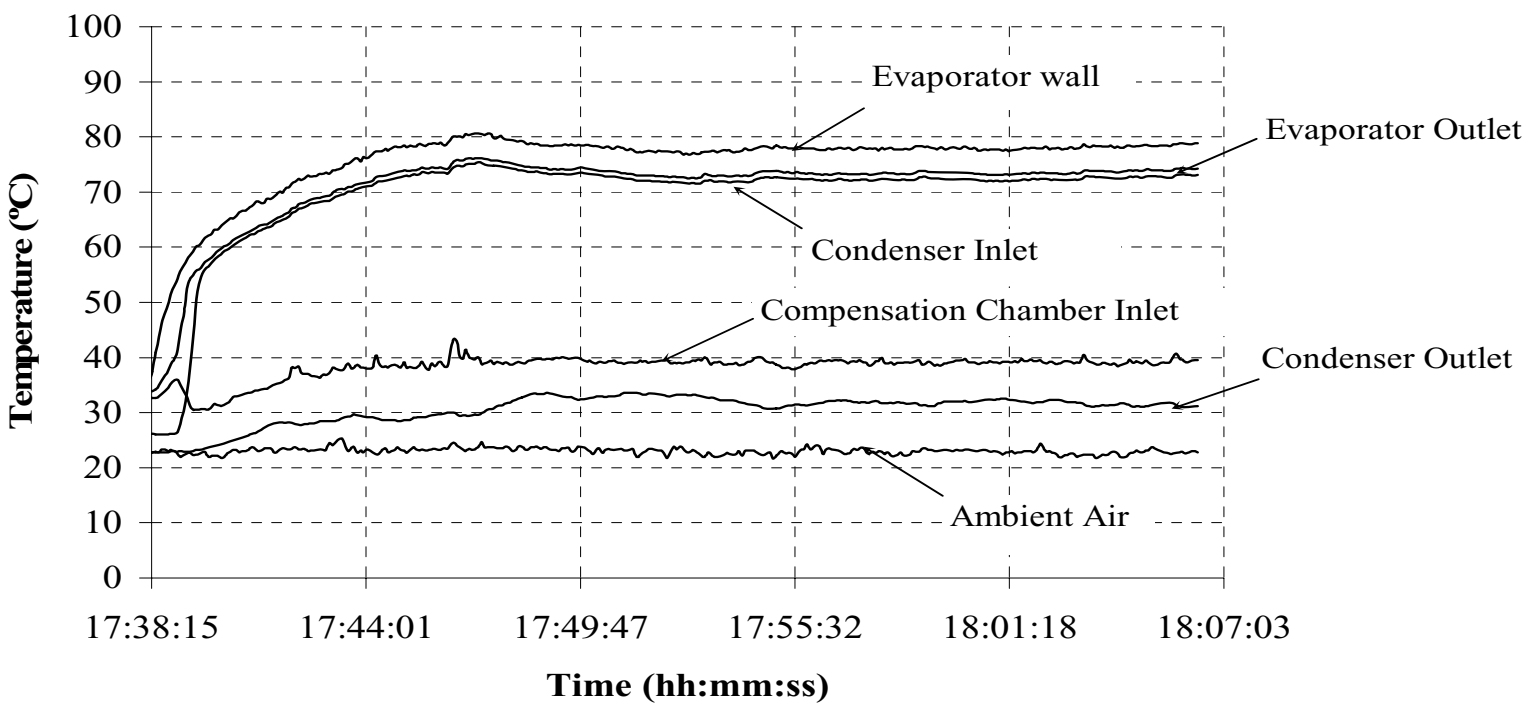

Fig 5. Start up of the mLHP under non-uniform heat load of $20 \mathrm{~W}$ 
Fig 6. shows the variation of the evaporator wall temperature as a function of the applied heat load for heat sources with different active areas. The decrease in the active heating area of the evaporator brings about an addition of the conductive resistance offered to the spreading of the heat to the entire heating face. It is evident from the graph that the mLHP was able to handle the conditions of local heating in which case only $10 \%$ of the evaporator active area was heated. For the range of applied heat load, the evaporator wall temperature for local heating (using $10 \times 10 \mathrm{~mm}^{2}$ heater) was within 1.0 to 1.2 times that of the uniform heating (using $25 \times 25 \mathrm{~mm}^{2}$ heater). This is made possible by the enhanced design of the capillary evaporator that decrease the conductive as well as

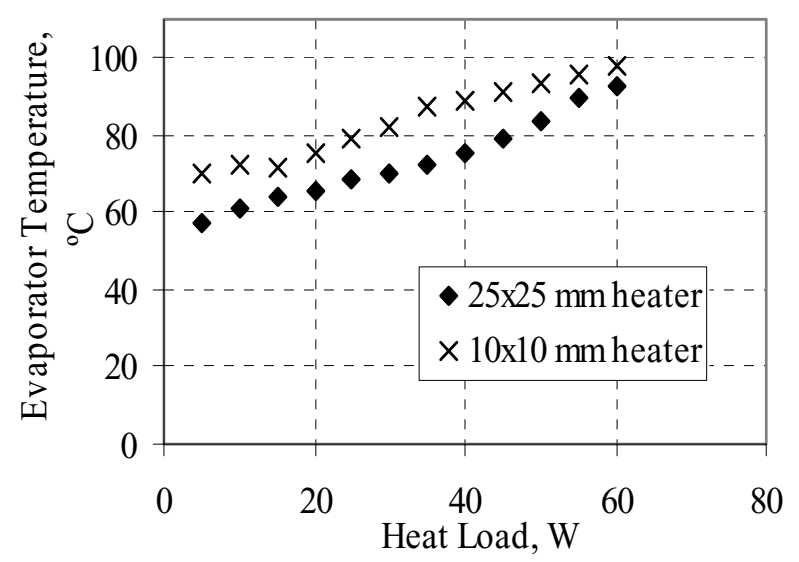

Fig 6. Relation between evaporator surface temperature and applied heat load for different heating modes

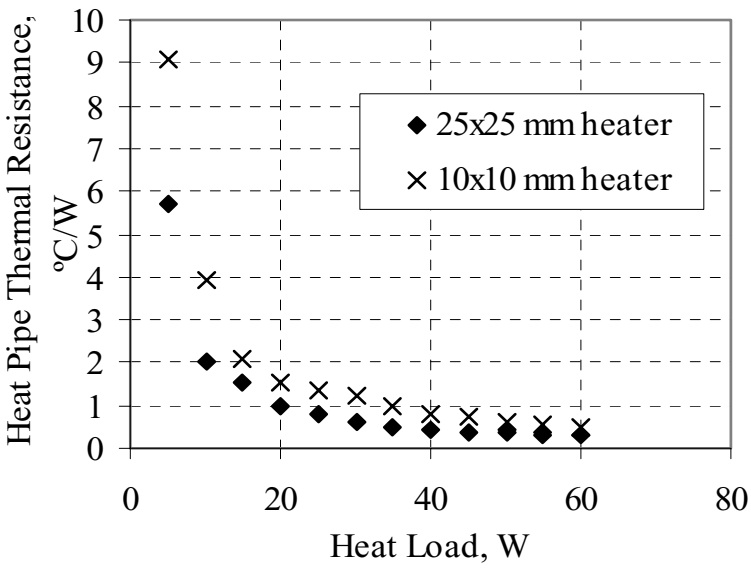

Fig 8. Heat pipe thermal resistance versus applied heat load for uniform and non-uniform heating mode convective resistance offered to the heat acquisition process. In the current design, the mLHP evaporator is made of copper material which due to its high thermal conductivity decreases the spreading resistance and promotes the efficient transfer of the heat from a hot spot without any local overheating of the evaporator surface. As opposed to the conventional heat pipe in which the heat is acquired at the evaporator through the liquid layer inside the wick structure, effective heat exchange is organised in the evaporator of mLHP by principle of inverted menisci. In this case, the evaporating surface of menisci is present close to the heated wall making it possible to reduce the thermal resistance of the evaporator zone and thus increasing the convective heat transfer coefficient.

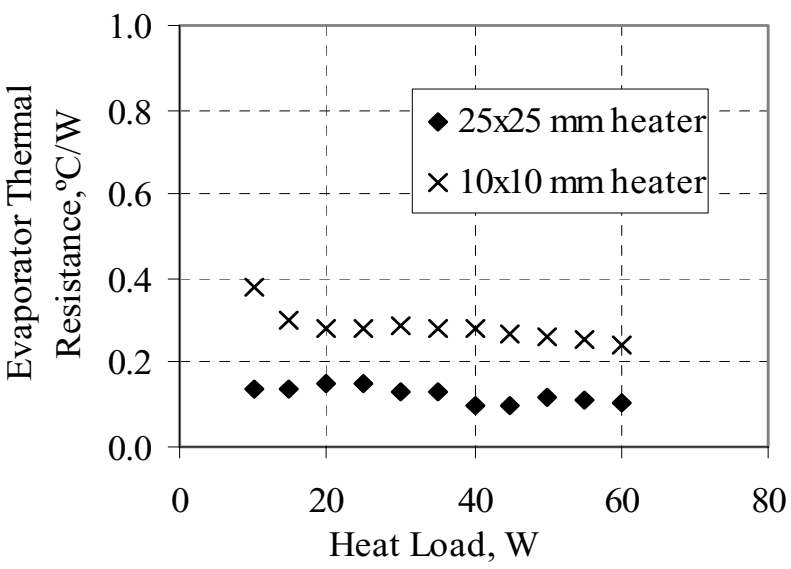

Fig 7. Evaporator thermal resistance versus applied heat load for uniform and non-uniform heating mode

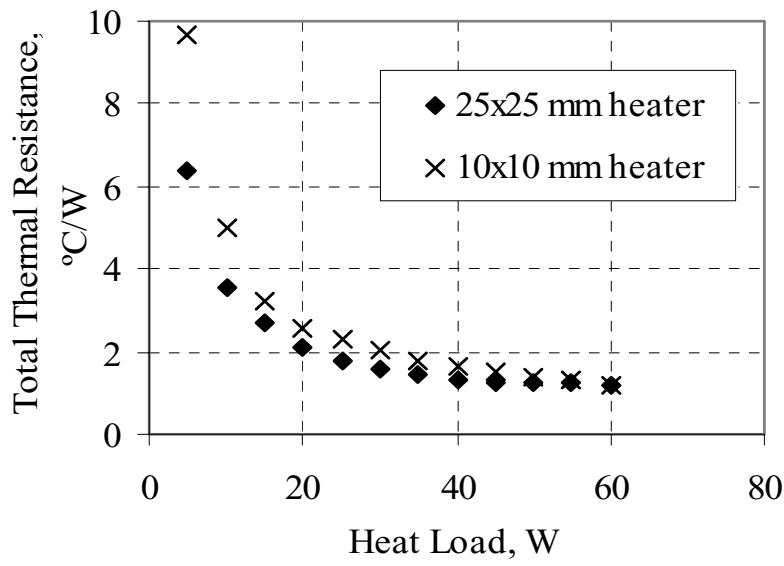

Fig 9. Total thermal resistance versus applied heat load for uniform and non-uniform heating mode 
For the designed prototype, heat transfer coefficient of the order of 10,000 to $20,000 \mathrm{~W} / \mathrm{m}^{2} \mathrm{~K}$ was achieved with both uniform as well as non-uniform heating modes in the range of applied power. The plot for the evaporator thermal resistance versus the applied heat load for two heating modes is shown in Fig 7. For the uniform heating $\mathrm{R}_{\mathrm{e}}$ lies in the range of 0.1 to $0.14{ }^{\circ} \mathrm{C} / \mathrm{W}$ where as for the local heating case value from 0.26 to $0.30{ }^{\circ} \mathrm{C} / \mathrm{W}$ were obtained. It is obvious from the above outcomes that the mLHP evaporator was able to manage the thermal loads of the local heating source efficiently. Fig 8 and 9 shows the trends for the total thermal resistance, $R_{t}$ and heat pipe thermal resistance, $R_{h p}$ with the change in the applied heat load.

With the uniform heating mode, minimum values of 1.18 for $R_{t}$ and 0.31 for $R_{h p}$ were achieved at $60 \mathrm{~W}$. The corresponding values for local heating mode are 1.36 for $\mathrm{R}_{t}$ and 0.62 for $R_{h p}$. The results clearly identify the superior thermal characteristics of the mLHP and its ability to acquire and transfer waste heat from compact microprocessors as well as chipsets with local hot spots.

\section{CONCLUSIONS}

The paper can be concluded as follow:

o mLHP with a flat disk shaped evaporator of $30 \mathrm{~mm}$ active face diameter and $10 \mathrm{~mm}$ thickness, was designed and tested for thermal management of up to $60 \mathrm{~W}$ heat load.

- The device was able to operate reliably under uniform heating mode and non-uniform heating mode in which only $14 \%$ of the evaporator active zone was heated. The evaporator surface temperature for the latter case was within 1 to 1.2 times the former case in the range of applied power.

- With the current design of the evaporator, heat transfer coefficient as high as 20,000 and evaporator thermal resistance, $\mathrm{R}_{\mathrm{e}}$ of $0.26^{\circ} \mathrm{C} / \mathrm{W}$ was achieved at $60 \mathrm{~W}$ heat load from non uniform heating source.

- At maximum heat load of $60 \mathrm{~W}$, the total thermal resistance, $\mathrm{R}_{\mathrm{t}}$ for the non-uniform heating mode was approximately 1.15 times that of the uniformly heating case.

o The results of experiments helped to identify the superior thermal characteristics of the mLHP and its ability to acquire and transfer waste heat from compact microprocessors as well as chipsets with local hot spots.

\section{REFERENCES}

1. Maydanik Y.F., 2004, Miniature Loop Heat Pipes, Proc of the $13^{\text {th }}$ Int. Heat Pipe Conf., Sept 21-25, Shanghai, China, pp.24- 37

2. Swanson T.D., Thermal control technologies for complex spacecraft, $13^{\text {th }}$ International heat pipe conference, 21-25 September 2004, Shanghai, China

3. Delil A.A.M., Baturkin V., Fridrichson Y., Khmelev Y., Zhuk S., 2002, Experimental results of Heat Transfer Phenomena in a Miniature Loop Heat Pipe with a Flat Evaporator, Proc of the $12^{\text {th }}$ Int. Heat Pipe Conf., Moscow, Russia pp.126-133.

4. Boo J.H., Chung W.B., 2005, Thermal Performance of a Loop Heat Pipe having Propylene Wick in a Flat Evaporator, Proc. of the ASME Heat Transfer Conference 2005, July 17-22, San Francisco CA, USA, ,

5. Pastukhov V.G., Maydanik Y.F, Vershinin S.V., 2003, Miniature Loop Heat Pipes for Electronic Cooling, Applied Thermal Engineering, Vol. 23, pp-1125-1135.

6. Chernysheva M.A., Vershinin S.V., Maydanik Y.F., 2002, Development and Test results of Loop Heat Pipes with a Flat Evaporator, Proc of $12^{\text {th }}$ Int. Heat Pipe Conf., Moscow Russia, pp. 134-138. 